Bicentennial in Shanghai. The Chilean pavilion and decoration as return to sender

\section{| RESUMEN |}

Más allá de los grandes proyectos arquitectónicos, cinematográficos o editoriales que han intentado celebrar nuestro bicentenario, el Pabellón chileno en la exposición de Shanghai manifestaría un paradojal modo de concebir el ejercicio rememorativo: mediante la pérdida de lo público y la dificultad para la constitución de una historia común. Tales fenómenos se desprenden de la particular estrategia curatorial del Pabellón, al proponer al interior doméstico como representante de la clase media del Chile neoliberal. La paradoja que esta imaginería domiciliaria logra exhibir, únicamente podía revelarse en una exposición internacional. Es allí, en el espacio del Otro, donde se visibiliza lo que la propia celebración bicentenaria, efectuada en el territorio nacional, no hace otra cosa que disimular: la aparente e inevitable banalidad de nuestro actual conmemorar.

\section{| ABSTRACT}

Beyond huge architectural, cinematographic and editorial projects celebrating our nation's bicentennial, 2010 Shanghai's World Expo Chilean Pavilion shows a paradoxical way to remember the loss of the public issue and the difficulty to define a common history. The origin of these phenomena is based on a particular curatorial strategy of the Pavilion, proposing the domestic interior as representative of the neoliberal Chile. The paradox behind this domestic imaginary, could solely reveal itself in an international exhibition, where the unavoidable banality of our bicentennial celebration can show its real dimension.

\title{
Bicentenario en Shanghai. El pabellón chileno y la decoración como retorno al remitente
}

a decoración está llena de detalles.

L Incluso podríamos afirmar que ellos son la textura fundamental que la constituyen a tal extremo que, si mirásemos a través de ella, no encontraríamos otra cosa que la repetición de la misma figura y nunca el esperado soporte en el cual, aparentemente, los ornamentos hunden sus raíces en la patria fuerte de la forma pura. Este texto que versa sobre la decoración, se abre justamente a partir de uno de esos pormenores que, en esta oportunidad, viene a circunscribir la escena que pretende evidenciar públicamente nuestra actual historicidad: la conmemoración bicentenaria. No obstante y al igual que en la economía estética del detalle, ha sido la sospecha de la inexistencia de un suelo firme y definitivo tras el decorado de la historia que asegure el arraigo de un ser-en-común, la que nos ha seducido a insistir en el mismo motivo ornamental a la hora de emprender algunas reflexiones historiográficas sobre la decoración en Chile.
Por ello, no comenzamos a partir de lo que podría atribuirse como sustancial para el ejercicio conmemorativo como son los rituales oficiales o los grandes proyectos arquitectónicos, cinematográficos o editoriales que hemos visto poblar a esta circunstancia. Por el contrario, partimos por una aparente nimiedad, por un adorno periférico que intenta coronar tangencialmente al acontecimiento: nos referimos a la muestra chilena presentada en la exposición internacional de Shanghai 2010. No solo porque su pabellón no tuviese la misión original de celebrar nuestros doscientos años de vida independiente, ni por el simple gesto de haberse ubicado fuera del territorio. Su carácter adyacente -y por lo mismo ornamental-se debe, más bien, al hecho de establecer un marco de representación para el ansiado "nosotros". Del mismo modo en que la orla decorada busca destacar a una obra de arte al eximirse de participar en ella, este marco concedería presentar a la República en el

\footnotetext{
Arquitecto de la Universidad de Chile, Magíster en Artes con mención en Teoría e Historia de la Universidad de Chile. Profesor de la Escuela de Arquitectura e Investigador del Centro de Estudios Urbanísticos y del Paisaje de la Facultad de Arquitectura Urbanismo y Paisaje (CEAUP) de la Universidad Central de Chile. Ha sido profesor en las escuelas de Arquitectura, Filosofía, Artes y Cultura Visual de la Universidad ARCIS y en la escuela de Arquitectura de la Universidad de Chile. Actualmente, ejerce el cargo de Coordinador de la Línea de Teoría e Historia de la Escuela de Arquitectura de la Universidad Central de Chile. Libros publicados por el autor son LA DERROTA DE LO COTIDIANO. Elementos para una ontología política del diseño contemporáneo (2013) editado por la Universidad Central y Señales de VIDA. De la decoración a la domesticidad en Chile. Reflexiones para una historiografía (2014), publicación financiada por el Fondo Nacional de la Cultura y la Artes del Gobierno de Chile. El presente artículo, constituye el primer capítulo de este último trabajo.
} 
1. Pabellón chileno Expo Shanghai 2010 Fuente: Fotografía de Macarena Gaete.

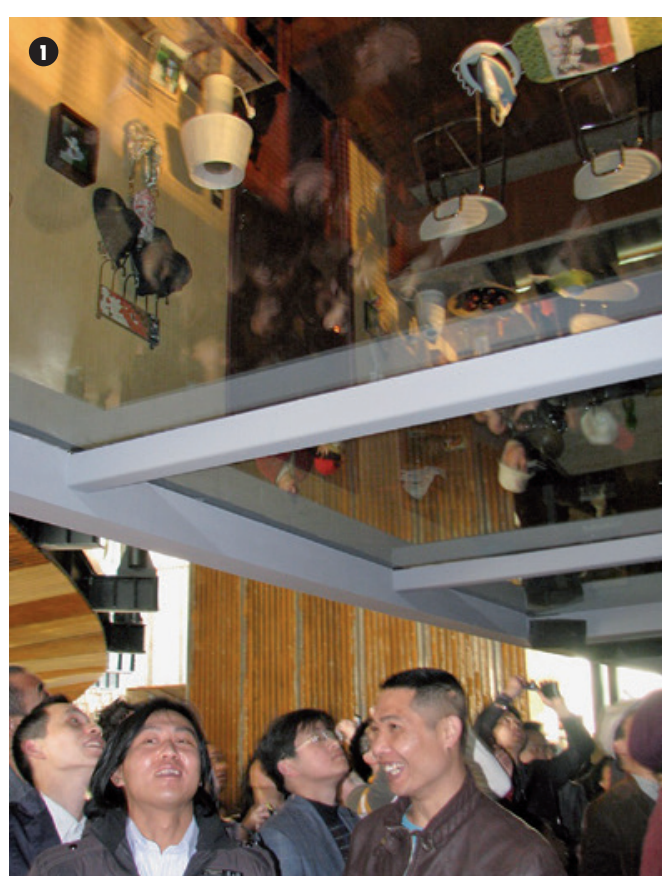

preciso instante en que su configuración no se encuentra plenamente ni dentro ni fuera de sus límites.

En principio, pareciera que no hay mejor lugar para husmear la complejidad simbólica de esta celebración, que un espacio de inscripción foránea. Quizás sea en el lugar del "otro" y las condiciones que este plantea, donde se movilizan con mayor esfuerzo los dispositivos discursivos, las retóricas identificatorias y las componendas representacionales que aspiran a dar cuerpo material a la gran fantasía nacional de lo "común". Por cierto, la participación de Chile en la exposición de Shanghai en 2010 parece ser, sin duda, el espacio privilegiado para abrir la interrogación sobre el modo en que el aniversario republicano se inscribe simbólicamente. Pero más aún, y más allá del simple hecho de la participación, es la manera en que tanto la arquitectura del pabellón chileno como la matriz discursiva que lo sostiene, pueden llegar a ser determinantes a la hora de cifrar la importancia que la "decoración interior" podría tener en el asomo imaginario del Chile del 2010. Nuevamente, un pequeño detalle.
En una primera medida, esta interpretación pareciese ser absolutamente exagerada y demasiado condescendiente con aquel "arte menor" o "técnica" subsidiaria a lo arquitectónico como bien podría definirse, desde el sentido común, a la decoración. Por el contrario, es la arquitectura la que tradicionalmente ha sido caracterizada como el modo más público y más histórico para acoger la presentación del sentido nacional en el territorio del otro. Sin embargo, no debemos olvidar que, justamente, fue el gran gesto espacial de la arquitectura el que colocó en el centro de la historia el aparentemente problema menor y "privado" de lo decorativo.

El célebre Cristal Palace de Joseph Paxton, pabellón de la exposición internacional de 1851 -la primera en su tipo en el mundo occidental- es una gesta espacial paradigmática no tanto por anticipar los materiales y el sistema constructivo que se volverán hegemónicos en el siglo XX, como son el hierro y el vidrio. Su heroísmo radica, más bien, en la singularidad de inaugurar en un solo lugar y al mismo tiempo, una gigantesca escena que permitiese comparecer de modo puramente contemplativo a todos los productos que, en rigor, nunca fueron pensados originalmente para tal condición. Maquinaria, artefactos manufacturados, esculturas, materias primas, mobiliario, etc., todas terminan igualadas en el mismo registro: la pura visibilidad. Pues bien, la consecuencia más fundamental de ese teatro de utensilios, es lo que Nietzsche (2000) denominó lapidariamente como "la falta de unidad de estilo". Si bien en general la obra de Paxton es considerada uno de los puntos cruciales para articulación de la épica del Movimiento Moderno, es la puesta en evidencia de la llamada "crisis del estilo" la que, en buenas cuentas, colocará la piedra fundacional de las soluciones estéticas, ontológicas y políticas del diseño moderno. En otras palabras, el principio de lo decorativo, entendido como el modo en que la pura forma se despliega alrededor de los usos instrumentales que circulan en la cotidianidad del habitar contemporáneo, será el núcleo problemático desde el cual surgirá el programa estético de la arquitectura y el diseño moderno, más allá de las nuevas materialidades propuestas por el pabellón de 1851.

Lo que en definitiva queremos afirmar con este clásico ejemplo, es que, desde sus inicios, hay algo que quedó indeclinablemente enganchado entre la grandilocuencia histórica de las exposiciones universales y la particularidad microscópica de las formas que habitan hasta los más recónditos lugares de la espacialidad privada y su comprimida temporalidad doméstica, como es la decoración interior. Precisamente, la evidencia de una falta de unidad de estilo en la vida (cotidiana), es la insoportable evidencia de que lo privado, una vez ingresado en el espacio de la exhibición pública, delata su interés mezquino, su ausencia de universalidad, su baja estatura civilizatoria.

\section{TESIS DE LA EXPOSICIÓN}

Por cierto esta misma lógica de acoplamiento polar entre la aspiración universal y la interrogación por la particularidad decorativa, parece haber quedado sellada hasta hoy en la propia contingencia del pabellón chileno en Shanghai. En una primera instancia, esta hipótesis del enganche entre extremos lo podemos encontrar en el núcleo de la interpretación que el mismo Comisionado General de la muestra, Hernán Somerville, pone en circulación:

Para muchos observadores, una parte importante del futuro de Chile está radicada en la forma en que nos vinculemos con la región de Asia-Pacífico. Por la red de acuerdos comerciales y de cooperación que Chile ha sabido concretar, por los lazos políticos y económicos que ha logrado desarrollar, tengo la convicción de que no existe otra nación en el mundo con una posición similar a la que hoy tiene Chile en el Asia-Pacífico (Somerville, 2010).

Si bien no se impone aquí necesariamente un eje polar que enlace lo alto y lo bajo -o lo público y lo privado- sí al menos se dibuja la puesta en imaginario de una línea virtual 
que comunica dos extremos mediante una aparente alianza económico-cultural, en la que Chile presta generosamente su liderazgo para servir de puente o de sutura. Ahora bien, si avanzamos más profundamente en la temática del evento, y por sobre todo, en la singular puesta en exhibición del pabellón chileno, veremos con claridad la manera en que la lógica de articulación de polos va adquiriendo su semblante.

"Mejores ciudades, mejor vida" es el lema de la convocatoria que la Expo Shanghai 2010 propone a los participantes. La interpretación de Chile ante ella, sin embargo, no deja de ser ampliamente paradójica. La tesis que se procura afirmar, en este sentido, es "explorar y aportar nuevas perspectivas para reenfocar el proceso de construcción de ciudad", frente a un lapidario diagnóstico del modo de vida alcanzado en nuestras metrópolis:

Privilegiamos la vivienda privada, la oficina privada, el transporte privado, los centros comerciales privados, la ocupación privada del suelo, la ocupación privada del tiempo, el consumo personal, las autopistas para uso del automóvil.

Los edificios se piensan como un conjunto de espacios privados, el espacio público es apenas funcional para el tránsito de las personas que se dirigen a sus espacios privados.

La construcción industrializada, si bien resuelve una parte de lo que se llama "el problema de la vivienda", produce otro: el paisaje de la uniformidad que limita la expresión de la singularidad humana (www.expo2010.cl, 2010).

La privatización de los modos de habitar junto con la construcción industrializada, cuestión que es tanto la causa como el efecto de lo anterior, nos conduce a un paisaje existencial uniforme que clausura la singularidad. Interesante conclusión, la privatización, lejos de promoverla, parece anular la auténtica manifestación de lo singular. Más allá del optimismo de la retórica empresarial de Hernán Somerville, aquí se coloca en primera línea la polaridad que ya anunciábamos: la destrucción del espacio público parece arrastrar inevitablemente a una crisis de lo privado. Si bien los términos en juego -público-privado- sí son señalados mediante un acoplamiento paradóiico -la destrucción de uno no hace triunfar a su opuesto sino más bien aniquilarlo- no es, por lo demás, la contrariedad más importante. La paradoja que en el fondo articula a aquella que el diagnóstico sobre el habitar urbano exhibe, es el hecho de que Chile no deja de enarbolarse como el paradigma mundial de la gran revolución neoliberal, donde la privatización es precisamente su eje central. No es necesario indagar demasiado en los estudios urbanos contemporáneos para colegir que son justamente las políticas urbanas neoliberales quienes han ocasionado el actual panorama de desertificación de lo público, a través del reemplazo de la planificación territorial por una cada vez mayor injerencia de la gestión privada ${ }^{[1]}$.

Desde este punto de vista, el discurso que cruza a la exposición chilena es, por lo bajo, una declamación culpógena ${ }^{[2]}$. Pero no es más que eso, una declamación. Precisamente la nula voluntad política del Estado para revertir los efectos que el diagnóstico deja entrever de manera dramática -"el paisaje de la uniformidad que limita la expresión de la singularidad humana" - no puede dejar otra solución que una compensación imaginaria ante la catástrofe de lo público. El Pabellón chileno precisamente cumple dicha función, puesto que su impronta estética le brinda la suficiente autonomía para plantear aquello que la realidad político-económica nacional no hace más que negar sistemáticamente.

No es en absoluto casual que quienes han participado fervientemente en la gestación de esa realidad-como el propio Comisionado General de la muestra, otrora máximo dirigente gremial de la Asociación de Bancos e Instituciones Financieras- al mismo tiempo de admitir el juicio lapidario de la problemática urbana que la fantasía representacional de la exhibición pone en obra, desplace la mirada hacia la aparente "realidad" de China.

La Expo Shanghai -nos advierte Somervilletiene por lema "Better City, Better Life" (Mejor Ciudad, Mejor Vida). Los organizadores han invitado a los distintos países de la comunidad internacional a participar en la Expo mediante propuestas que llamen a la reflexión y que puedan generar un debate constructivo sobre cómo redefinir las fronteras de lo urbano, recuperar más espacios para las relaciones humanas y la convivencia de las personas. China es, por lo demás, un país ideal para iniciar una muestra como la propuesta, ya que se trata de un país donde el $60 \%$ de la población vive en zonas rurales y los objetivos de desarrollo obligan a generar espacios urbanizados y sustentables (www.expo2010.cl, 2010).

[1] Las principales transformaciones vividas por la ciudad contemporánea, cuyo eje central es la crisis de la planificación territorial, es un fenómeno indisociable de la deflación del Estado benefactor y la consiguiente implementación de políticas neoliberales. Gran parte de este nuevo escenario se debe al "nuevo trato" entre globalización y localidad: el anclaje entre financiarización de la economía mundial y los negocios inmobiliarios, por cuyo acoplamiento se van gestando tanto las nuevas lógicas de ordenamiento territorial como también los mecanismos de gestión política del espacio, como es la denominada "gobernanza urbana" (Yáñez, G.; Orellana, A.; Figueroa, O.; Arenas, F., 2008).

[2] Frente a una letanía de lamentaciones, en la tesis temática de la exposición titulada "Ciudad de las relaciones" organizada en ocho principios básicos, aparecen todos los lugares comunes del discurso académicamente correcto, pero que jamás cuestiona la fibra del modelo: "Mientras más intercambio positivo haya en esa red, más crecimiento, más desarrollo, menos derroche, más calidad" (primer principio); "Lo privado debe mantenerse en la justa medida de lo necesario y suficiente" (segundo principio); "La proporción de los grandes edificios con la escala de su llegada al suelo; la velocidad del tránsito rápido con la lentitud del pie; los millones de habitantes con la familiaridad de los pequeños barrios" (quinto principio); "Lo público no debe ser segregado, al contrario, la valoración de lo público es esencial para igualar las oportunidades de todos de crear valor y acceder a una buena calidad de vida" (sexto principio); "La ciudad debe proveer lugares donde las relaciones no premeditadas tengan ocasión de ocurrir" (séptimo principio); "La fiesta pública, la actividad cultural callejera no son accesorios a la vida laboral que prevalece en la ciudad, sino que son sustanciales a la vida de las personas" (octavo principio) www.expo2010.cl. 
2. Pabellón chileno Expo Shanghai 2010. El pozo de las antípodas. Fuente: Riolab, Laboratorio de Ideas.
3. Pabellón chileno Expo Shanghai 2010. El pozo de las antípodas. Fuente: Riolab, Laboratorio de Ideas.
Como vemos, ni una sola palabra del banquero sobre las genuinas causas económicas y políticourbanas del paisaje de uniformidad que limita la expresión de la singularidad humana. A pesar de que el desplazamiento de la culpa se traslada a los serenos marcos de la exhibición, en ningún momento en ella se hace mención explícita a la verdadera raíz del problema, es decir, al hecho de que Chile sea el experimento emblemático de la ideología económica de Milton Friedman y sus consecuencias urbanas. Por el contrario, junto al discurso culpable de la catástrofe de lo público, se ostentan las bondades globalizadoras del neoliberalismo chileno y su flamante función mediadora del eje Asia-Pacífico.

Junto a esta paradoja que lamenta los efectos y celebra las causas de la deflación de lo público del habitar urbano nacional tenemos, paralelamente, una interesante puesta en escena de una nueva polaridad. Esta vez ya no se concentra en la tensión inmanente al modelo económico-cultural del Chile actual, sino que se dibuja en torno a la alteridad con el país organizador de la exposición. En otras palabras, esa tensión inmanente al modelo chileno, estaría de algún modo desplazada a aquella que es posible reconocer entre Chile y su Otro.

\section{EL POZO DE LAS ANTÍPODAS}

Haciendo uso del conocido mito popular de que si uno cava un orificio lo suficientemente profundo en Chile terminaríamos llegando a China, el pabellón ha simulado un pozo de dos metros de diámetro por un metro ochenta de profundidad, en cuyo fondo se presenta una gran pantalla en la que se puede ver, on-line, a Chile y su gente. El nombre de este dispositivo es el de "Pozo de las antípodas". Como sabemos, el concepto de antípoda da cuenta de aquel lugar de la superficie terrestre diametralmente opuesto a una determinada posición de referencia, representando el punto más alejado respecto de esta. Aparentemente lo que esta instalación pretende manifestar es el aparecer de los curiosos rostros del otro lado. Pero no es únicamente mediante el juego de las fisionomías que, en su distinción racial y cultural,

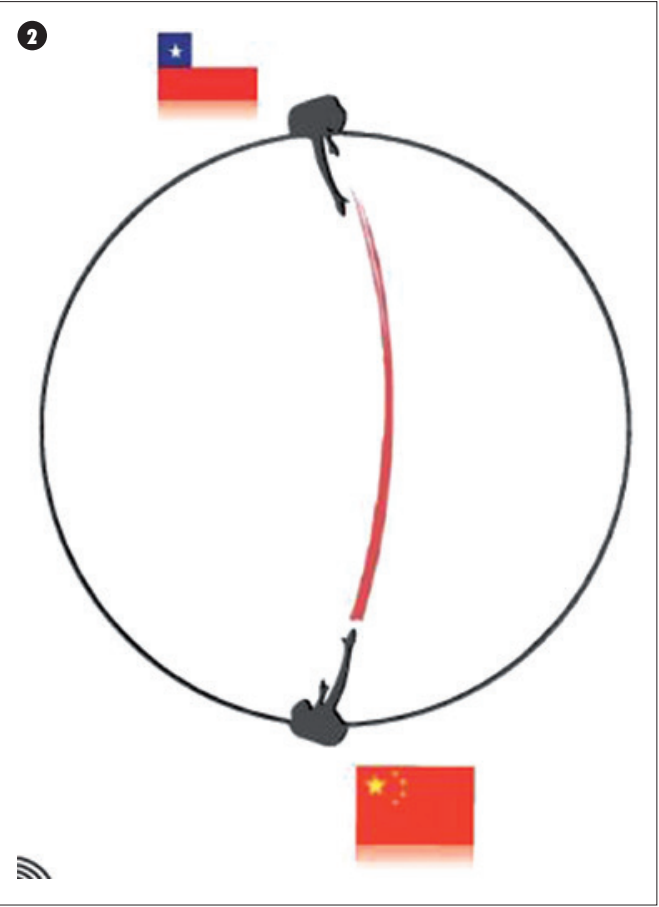

se pretenden remarcar las diferencias. Como lo explican sus mismos creadores:

Este pozo es en realidad un medio de comunicación de dos vías, ya que en el centro de su pantalla hay una cámara de video que registra las imágenes de las personas que observan el fondo del Pozo en China y las proyecta en el Tótem donde está instalada la cámara que registra las imágenes desde Chile. Es decir, las personas que son grabadas en Chile, pueden ver a los visitantes del pabellón chileno en Shanghai. Si bien el "Pozo de las antípodas" es un lugar fijo en China, en Chile el gran ojo que nos observa recorrerá lugares públicos y privados por Santiago y sus alrededores, de acuerdo a una programación definida cuidadosamente (www.expo2010.cl, 2010).

Si bien conceptualmente las antípodas definen una polaridad simétrica, en el presente caso la propia configuración del dispositivo se encarga de romperla. Mientras los asistentes a la exposición en Shanghai dejan asomar sus rostros a través del pozo desde el espacio

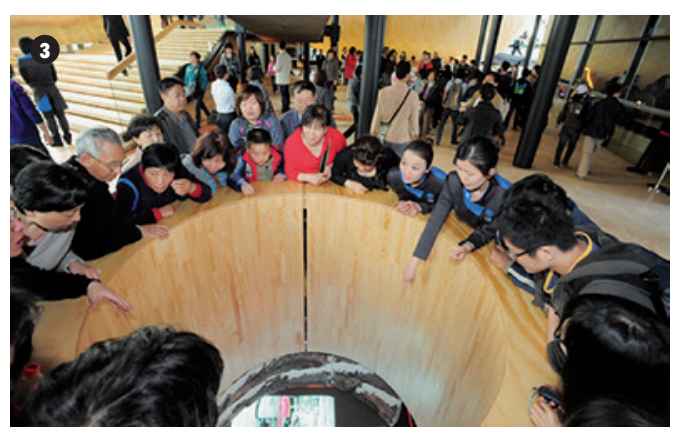

público que el pabellón en sí representa, los chilenos inscriben los suyos siempre en función del recorrido de la cámara-tótem que los va registrando. Lo que allí se captura, por tanto, no es principal ni únicamente sus semblantes sino más bien un "paisaje de rostros", o mejor aún, los rostros del paisaje santiaguino y sus alrededores. Que tras el desplazamiento constante de la cámara de acuerdo a una programación "cuidadosamente definida", el rostro comparezca primordialmente como paisaje no es en absoluto baladí. Precisamente, dicha operación viene a reafirmar la estética dominante del imaginario turístico donde la imagen-país, tramada por el verosímil paisajístico, no solo descansa en la fisionomía territorial y los emblemas sino también por la fauna, las comidas y los cuerpos. Cada uno de estos elementos, con sus particulares sellos significantes, conforman el gran sintagma geográfico-visual de la nación. Sin embargo, la ficción que el Pozo de las antípodas propone no deja de reproducir, a otra escala, la naturaleza paradójica que ya hemos destacado respecto de la exposición. Al contrario de lo que pueda significar para el sentido común, esto es, un paraje abierto y por tanto de dominio público, el paisaje que se pretende reconstituir en la antípoda nacional se nutre también del recorrido por lugares privados de Santiago y sus alrededores. En buenas cuentas lo privado, lejos de ser considerado aquí como suspensión del paisaje -o su remanso-, es más bien comprendido como un componente integral de su continuidad.

Como consecuencia de ello, la propia intimidad tornada geografía nacional no podía menos que 
instalarse con pleno derecho a su exhibición. De hecho, tal como explícitamente lo reconoce Macarena Gaete, arquitecta participante en la muestra del Pabellón, destaca que

incluso la fachada exterior, además de llamar poco la atención de los visitantes que deambulan por la Expo, resulta una imagen construida bastante conocida [...] Pero lo que sucede al interior del pabellón ya es otra historia. Si afuera la arquitectura no hacía volver la vista, adentro los cautiva (Gaete, 2010).

\section{LA INTIMIDAD DE LA CLASE MEDIA}

Si al acento en la interioridad como matriz central de la estrategia general de la exhibición, le sumamos los elementos estructurantes fundamentales de la ficción del pozo que hemos revisitado, obtendremos la lógica fundamental que viene a condensar aquella polaridad que cruza a la economía conceptual del Pabellón. No obstante, esta lógica no se desprende solo del análisis que aquí hemos querido adelantar, sino que también tiene su específico modo de ponerse en obra.

De las cuatro primeras salas que corresponden al proyecto temático de la consultora "El otro lado", en la segunda sala

los visitantes son sorprendidos con un departamento invertido sobre ellos. Pretendiendo aludir a la distancia y la posición física invertida de Chile y China, se representa un departamento de la clase media chilena. Como complemento, al frente corren videos de gente común simulando ser el edificio vecino con sus habitantes viviendo cotidianamente (www. plataformaarquitectura.cl, 2010).

Lo que podemos observar en este particular gesto instalatorio, es que en honor a la polaridad geográfica entre Chile y China que la obra manifiesta, podemos reconocer la propia distancia que tensiona internamente al modelo económico, político y cultural del Chile actual, y que hemos descrito como un particular modo de manifestación estética de la culpa. Con el fin de hacer plausible esta hipótesis, recorreremos pausadamente los ingredientes que la constituyen.

En primer lugar tenemos que la obra remarca un intervalo entre extremos: la distancia entre Chile y China. Sin embargo esta distancia está ficcionada mediante una estrategia análoga al "Pozo de las antípodas", puesto que el objeto exhibido se encuentra en posición invertida. En segundo lugar, dicho objeto es precisamente un espacio interior, pues se trata de la ambientación característica de un departamento de la clase media chilena. Ya hemos reparado en el énfasis que el pabellón ha hecho del interior como estrategia exhibitiva fundamental y que aquí no hace sino reafirmarse metonímicamente, al concebirse al interior doméstico como lo propiamente representativo de lo nacional. Pero es gracias a esta puesta en escena puramente visual del interior domiciliario, lo que convierte a la decoración en su principal protagonista, entendida aquí como el "detalle" particular del habitar urbano en que la clase media administra estética y funcionalmente su intimidad.

En un principio, vimos que la especificidad de los rostros, así como de los lugares privados capturados por el "Pozo de las antípodas", se ofrecen primordialmente como paisaje donado a la contemplación pública. Precisamente la pura puesta en exhibición de la intimidad doméstica hace del interior no un simple fragmento -o detalle- del mundo, sino un paisaje como tal. Aquí encontramos, quizás, la polaridad en su más evidente manifestación. Al mismo tiempo en que el interior se torna paisaje, lo privado se trasfigura en público o, mejor dicho, se termina emplazando en el "lugar vacante" de lo público.

Pues bien, de la tensión geográfica entre China y Chile representada en el departamento "en antípoda", pasamos a la tensión interna del propio modelo político-económico chileno, implícitamente manifestada en la tesis general de la exposición: "Privilegiamos la vivienda privada, la oficina privada, el transporte
4. Pabellón chileno Expo Shanghai 2010. Fuente: www.portable.cl

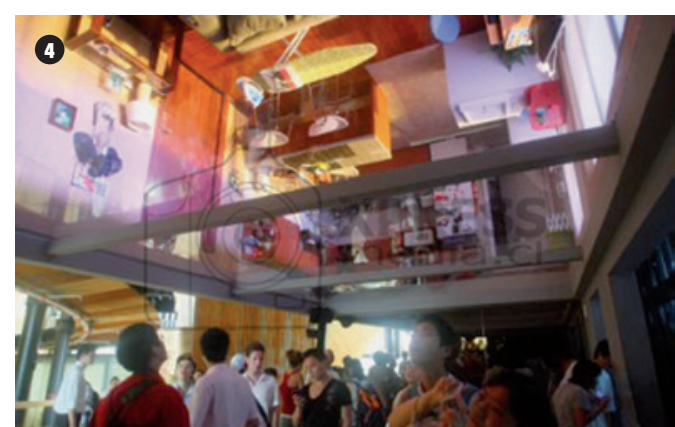

privado, los centros comerciales privados", etc. en donde "la construcción industrializada", si bien resuelve una parte de lo que se llama "el problema de la vivienda", produce otro: "el paisaje de la uniformidad que limita la expresión de la singularidad humana". En definitiva, la disyunción que forja la desertificación de lo íntimo, no es otra cosa que la manifestación radical de su triunfo, mediante el cual las políticas neoliberales van suplantando el habitar público metropolitano.

A este respecto es necesario recalcar que lo que vuelve particularmente interesante a esta instalación, no es simplemente la exhibición cuasi-antropológica del interior doméstico. Es sobre todo el modo invertido en que esa pieza se expone, la que podría darnos la clave del desplazamiento que va desde una polaridad entre naciones, a una que tensiona internamente al modelo cultural del Chile contemporáneo, donde la manifestación culpógena del trance público-privado parece conjugarse a través de la decoración interior. En otras palabras, solo un particular tipo de relación inversa con el Otro puede donar el sentido profundo de nuestro propio conflicto identitario.

\section{EL RETORNO AL REMITENTE}

Esta específica dinámica relacional podríamos interpretarla en términos psicoanalíticos, a partir de una figura que Jacques Lacan desarrolla en su seminario sobre "La carta robada". Allí expone la dinámica de lo que se denomina el "retorno al remitente", entendido como la lógica que involucra toda comunicación intersubjetiva, 
en la que el emisor siempre "recibe del receptor su propio mensaje bajo una forma invertida" (Lacan, 2008).

La ejemplificación de esta dinámica es posible de reconocer en las fórmulas radicales como "Tú eres mi maestro" o "Eres mi mujer", en cuanto significan plenamente lo contrario de lo que articulan en el presente de la palabra. Previamente a ser declaradas, estas sentencias ya han reconocido tácitamente al Otro, en virtud de lo cual la enunciación resulta justamente la respuesta invertida a tal reconocimiento. En efecto, el sujeto que interpela al Otro diciéndole "Tú eres mi maestro" le está formulando implícitamente "Yo soy tu discípulo", aunque la realidad concreta de la palabra recaiga en la primera enunciación. Para Lacan, toda palabra se sustenta en este reconocimiento previo del otro; más aún, el lenguaje mismo sería en su articulación la respuesta a un Otro absoluto, al cual necesariamente se dirige y que está más allá de él. De otra forma, "la palabra siempre incluye subjetivamente su respuesta" (Lacan, 2008) de modo que toda alocución se constituye como si fuese una réplica a ese gran Otro que tácitamente se asoma en el discurso.

Es en vistas a este "retorno al remitente" el que haría plenamente plausible lo que referimos en un comienzo: no hay mejor lugar para comprender la pretensión de identidad que involucra nuestra celebración bicentenaria, que el modo en que ella se inscribe en un espacio foráneo. El pabellón chileno es, de hecho, palabra articulada que se encuentra literalmente en el territorio del Otro. Pero más allá de esta evidencia general, lo que aquí proponemos como la cifra más representativa de tal acontecimiento, es la metáfora que encierra la particular operación instalatoria del departamento invertido.

En una primera mirada, debemos reparar en el modo explícito en que el gesto formal se dirige al Otro. A través de una puesta en inverso de un hábitat cotidiano, la obra constituye, en efecto, el marco presente de la enunciación. Si ocupamos la ejemplaridad de las fórmulas antes señaladas, habría que decir que la sentencia que ella dirige a los asistentes se articula en la fórmula "tú eres mi antípoda". En apariencia, a quienes se habla por medio de este sintagma, es a una China que Chile cree asumir como la receptora idónea de su mensaje, esto es, una potencia plenamente integrada al capitalismo global, orden al cual ambas naciones supuestamente pertenecen y cuyos contrastes, más allá de los evidentemente culturales, son únicamente geográficos: aunque habitan invertidamente en los extremos del planeta, participan del "mismo" mundo.

La virtual disminución de las distancias, sin lugar a dudas, ha sido parte de los efectos latamente destacados y celebrados de la globalización. No obstante y tal como el Situacionismo en su momento reparó, no solamente el espacio sino también el tiempo de la producción económica, se manifiesta en todo el planeta como "el mismo día". En la medida en que el "tiempo irreversible unificado es aquel del "mercado mundial", el tiempo mismo se torna "el del espectáculo mundial" (Debord, 1995).

Qué mejor ejemplo de ello que la exhibición de un interior doméstico para dar cuenta de que, a pesar de la singularidad de cada país, el participar del "mismo día" del espectáculo mundial-que la Expo Shanghai escenifica-, demuestra que la única diferencia restante entre ellos es el hecho físicamente contingente de estar invertidos respecto del planeta. Más aún, si verdaderamente fuese posible excavar el "Pozo de las antípodas" llegaríamos al otro lado convencidos -y quizás decepcionados- de que, finalmente, habitamos exactamente el mismo "mundo".

Ahora bien, si en una segunda mirada consideramos que el habla presente -es decir, la instalación aquí analizada- no es sino la respuesta a un mensaje inverso que tácitamente viene del Otro, el panorama resulta completamente diferente. Es ese mensaje el que nos sitúa en el lugar desde el cual se elabora finalmente la respuesta en tanto puesta en obra. En efecto, si esta última dice "Tú eres -solamente o nada más que- mi antípoda", dado que en el fondo participamos del mismo orden global, es porque Chile previa e implícitamente ha planteado a su Otro exactamente lo contrario: "Yo soy tu antípoda". A diferencia de lo que podría pensarse, aquí ya no se trata simplemente de una inversión simétrica en donde una de las partes se coloca ante su opuesto en igual medida. En otras palabras, "yo soy tu antípoda" no indicaría la diferencia meramente física o geográfica del estar al revés en el mismo mundo. Por el contrario, Chile se concibe como antípoda radical respecto de China bajo un sello, al mismo tiempo que enorgullecedor, también profundamente traumático. Ante el comunismo triunfante que China viene a representar -independientemente de su fórmula de éxitoChile es la indiscutida vanguardia mundial de la apuesta neoliberal que, por cierto, ha surgido a partir de un desastre. Bajo esta identificación previa, Chile elabora su respuesta en tanto inverso del Otro pero, insistimos, bajo un carácter de diferencia que supera sin duda la simple oposición geográfica de la antípoda.

Si desde este punto de vista exploramos la palabra que Chile coloca en circulación mediante la obra analizada, descubriremos dos cuestiones fundamentales. Por una parte la oposición fundamental que la separa de China -y del imaginario comunista en general- $y$, por otra, la profundidad de los efectos del trauma que lo constituye en modelo experimental del neoliberalismo.

Respecto de lo primero, sin duda lo que más salta a la vista es la apelación a la metáfora del típico interior doméstico de la clase media urbana. Es en honor a la cualidad simbólica de dicha metáfora donde podemos rastrear la naturaleza de la oposición. Precisamente, frente al hábitat privado de lo domiciliario, encontramos el gran espacio público que la planificación centralizada del Estado socialista concibe como eje fundamental del orden metropolitano. Por su condición de articulador de dicho orden, por su amplitud y, en definitiva, por su vocación pública, puesto que es y debe ser visible a todos los ciudadanos, aquel espacio es ante todo un paisaje. En nuestro caso, el interior doméstico en exposición se encuentra 
sin moradores. Por lo mismo, lo que se da a ver allí es la comparecencia exclusivamente formal de los artefactos que coronan la vida cotidiana, independientemente de sus prestaciones utilitarias. En virtud de ello, lo que se manifiesta en esa pura escena formal del ambiente, es la decoración interior. En este sentido, no habría que definir a esta última como una práctica estéticamente consciente de sus acciones, sean estas aficionadas o profesionales, ni mucho menos como un simple suplemento -o pasatiempo-añadido a las verdaderas urgencias del habitar diario. Por el contrario, se trata de la compleja cristalización de las operaciones culturales que "sujetan" a los moradores, puesto que al mismo tiempo de subjetivarlos, los inscribe en la estructura social. De hecho, se trata de un interior doméstico "típicamente" de clase media, donde la idea de "tipo" viene a revelar un patrón cultural y estético de enclasamiento. Dado que se trata justamente de un tipo, es decir, de un esquema o figura, es que la decoración interior aquí se convierte fundamentalmente en "paisaje". Pero no solo porque lo mostrado por ella se dona a la pura contemplación, sino porque el paisaje como tal está indisociablemente unido a la subjetividad:

El Paisaje no es, por lo tanto, lo que está ahí, ante nosotros, es un concepto inventado o, mejor dicho, una construcción cultural. El paisaje no es un mero lugar físico, sino el conjunto de una serie de ideas, sensaciones y sentimientos que elaboramos a partir del lugary sus elementos constituyentes [...] La idea de paisaje no se encuentra tanto en el objeto que se contempla como en la mirada de quien contempla. No es lo que está adelante sino lo que se ve (Maderuelo, 2006, p. 38).

A pesar de ser un entorno eminentemente privado, la decoración se constituye aquí en paisaje al momento de ofrecerse como algo públicamente destinado a la contemplación. Pero si asumimos que necesariamente el paisaje involucra una subjetividad, sin duda la alusión a la clase media chilena no es para nada insignificante. Si bien en Chile los sectores medios tuvieron su matriz primordial de constitución en el Estado (Candina, 2009), bajo la modernización neoliberal, la figura del empleado público debe ser sustituida por nuevos dispositivos que permitan reconstituir su identidad de clase, esta vez, desde prácticas privadas, tal como pueden llegar a ser los modos de agenciamiento de los espacios domésticos. De hecho, si tomamos como referencia las "típicas" operaciones de arreglo que la clase media chilena realiza en sus domicilios para efectos de realizar el "sueño de la casa propia", es posible afirmar que

el barrio y la vivienda no deben ser considerados aquí solo como espacios que reflejan la identidad de distintos grupos sociales (en este caso los sectores medios), sino también como un componente central en la creación e identificación de estos grupos (Aristía, 2009, p. 82).

En tanto inversión del mensaje que proviene del Otro, la puesta en escena del interior doméstico no puede menos que significar el desplazamiento desde del paisaje de lo públicoestatal, propio de la metrópolis socialista, al paisaje privado-decorativo del interior doméstico nacional, en tanto proceso de re-subjetivación postestatal de la clase media. Sin embargo, el preciso instante en que la obra se articula, el gran Otro a quien previamente se le ha reconocido su condición de opuesto radical, pasa a reducirse a la minúscula diferencia geográfica de la antípoda. De este modo, la propia puesta en escena invertida convierte a China en un partner más de la modernización neoliberal chilena, cubriendo -y reprimiendola diferencia originaria.

Sin duda, hay en este juego de inversiones algo de profunda densidad que finalmente culmina en el virtual equilibrio entre los opuestos. En efecto, todas las excentricidades discursivas que reducen al comunismo chino a una mera monstruosidad político-económica como "Capitalismo de Estado" o "Capitalismo comunista", se deben no tanto a los esfuerzos retóricos que los ideólogos liberales extraen de sus propias convicciones sino, sobre todo, a las conclusiones que estos mismos pueden hacer desde una lectura del marxismo leninista clásico. Sobre aquel piso hermenéutico, sin duda, no queda otra cosa que abrazar la fantasía del triunfo total y definitivo del capitalismo. Sin embargo, desde las formulaciones de la dialéctica maoísta el proceso chino puede ser entendido de manera completamente distinta: paradójicamente, la lección final de la Revolución Cultural es que únicamente

el capitalismo puede desarrollarse plenamente no en el reino sin trabas del mercado, sino solo cuando un obstáculo (desde la intervención mínima del Estado del bienestar hasta el dominio político directo del Partido Comunista, como sucede en China) pone límite a sus tropelías (Žižek, 2011, p. 197).

A contrapelo de las interpretaciones liberales, ¿No sería acaso posible pensar que la pretensión de la China comunista es, aunque suene contradictorio, absorber y asimilar las lógicas capitalistas como única medida de someterlas y finalmente vencerlas? De hecho, como lo argumenta Žižek,

al margen de todas las burlas superficiales y analogías baratas, hay una profunda homología estructural entre la permanente autorrevolución maoísta, la continua lucha contra la osificación de las estructuras estatales y la dinámica inherente al capitalismo (lbíd., p. 204).

No obstante, continúa,

el resultado fatídico último de la Revolución Cultural, su catastrófico fracaso y la catastrófica inversión que ha padecido con la reciente transformación capitalista no agota lo real de la Revolución Cultural: la eterna ldea de la Revolución Cultural sobrevive a su derrota en la realidad sociohistórica, sigue llevando la subterránea vida espectral de los fantasmas de las utopías fallidas que se aparecen a las generaciones futuras y aguardan con paciencia su próxima resurrección (lbíd., p. 214). 
Así como la idea de la revolución permanente que Mao no se atrevió a llevar hasta sus últimas consecuencias al no permitir la disolución total de la tutela del Estado-partido, podemos decir que, de manera análoga e inversa, el propio dogmatismo neoliberal del Estado mínimo no puede menos que cuestionarse, pues la completa desregulación y el despliegue infinito de lo privado, es el límite para el propio avance capitalista. Precisamente el progresivo posicionamiento de China como potencia mundial parece ser el ejemplo de aquella necesidad, situación que no podría menos que incomodar a la ortodoxia de Chicago.

Ahora bien, si de la posición originaria desde la cual Chile se descubre como antípoda de la dictadura del Estado-partido retornamos, a través de la respuesta "en obra", al equilibrio simétrico-aunque en inverso- entre dos órdenes que se asumen fatalmente como habitando el "mismo mundo", es porque hoy en día el capitalismo parecer ser el trasfondo naturalizado en el cual todas las cosas parecen reflejarse. Es esta continuidad de mundo, a pesar de la extrema diferencia, la que vuelve plausible el hecho de que sea la domesticidad el punto de conexión entre ambas naciones: en el fondo de nuestras intimidades, no somos más que el doblaje del otro en un espejo que hoy cruza todo el planeta.

Por cierto el costo de ese mutuo avistamiento especular está cifrado por la catástrofe. Por un lado, encontramos el fracaso de la revolución cultural que ha conducido finalmente a la reconversión de China al capitalismo mundial. Por otro, en el caso de Chile, la revolución neoliberal y su lógica privatizadora ha desatado una crisis del espacio público urbano, tal como la propia exposición lo plantea:

La ciudad "privada" moderna atenta contra su esencia y termina aislando al ser humano, una profunda contradicción que produce los problemas antes mencionados [aquellos relativos a la vivienda, el transporte, el uso de suelo privados, junto a la reducción del espacio público a solo una economía funcional de tránsitos, etc.] [...] La tesis de
Chile es que la ciudad de hoy tiene que cambiar sus paradigmas para adaptarse al nuevo estado de desarrollo del ser humano (www.expo2010.cl, 2010).

\section{LA CATÁSTROFE DE LA HISTORIA}

Más allá de la tensión espacial públicoprivado que tanto la instalación como la tesis de la muestra colocan en evidencia, está la querella sobre el tiempo. La propia puesta en escena del interior doméstico implica, de hecho, una respuesta inversa al reconocimiento de la temporalidad del Otro. Junto a ese reconocimiento previo y al igual que en el espacio, lo que adviene es un cierto fracaso que, sin embargo, no sucede en el tiempo sino que más bien le ocurre al tiempo mismo.

Bajo la pretensión de subordinar los acontecimientos nacionales a la voluntad de control político de la producción económica, la China comunista aspira a ser propietaria de su Historia. El tiempo del socialismo es siempre un tiempo de lo pendiente, de una emancipación que el pueblo se ha prometido a sí mismo. Es en virtud de esa deuda que el presente adquiere su verdadero rostro y justificación. Ello es el fruto primordial de la conquista revolucionaria puesto que, tal como lo señala Debord, la lucha por la apropiación social de la temporalidad se constituye en la trasformación del tiempo cíclico del trabajo en aquel tiempo irreversible que los amos forjan para sus propios intereses (Debord, 1995). El socialismo, en este sentido, no es otra cosa que la democratización de esa irreversibilidad, en el momento en que el control popular de la producción supera la penuria cíclica de la labor cotidiana de los trabajadores.
Desde esta perspectiva, habría que decir que el fracaso de la revolución cultural que nos advierte Žižek, es la subversión de aquella conquista: el definitivo sometimiento de la Historia nacional al tiempo irreversible del mercado que "se manifiesta sobre todo el planeta como el "mismo día'" (Debord, op cit., p. 96). En la medida en que esa manifestación, en rigor, no obedece a control humano alguno, entonces ya no puede ofrecer otra figura más que la del tiempo cíclico. Más allá de la aparente irreversibilidad de la acumulación mercado, sea en la periodicidad de sus crisis y recuperaciones, o en la revolución constante que el capitalismo debe realizar para sobrellevar sus propias contradicciones ${ }^{[3]}$.

Aunque en evidente aceleración, este tiempo global se encuentra eximido de toda virtud teleológica, de allí su cualidad de suspensión que extrañamente involucra a pesar de la frenética obsesión contemporánea por la innovación. De la misma manera en que opera el reemplazo de una mercancía sin otro telos que el ensanchamiento de los mercados, los propios acontecimientos reducidos al estatuto de "noticias", ahora parecen sucederse en medio de la impotencia de una inteligibilidad definitiva, bajo la cual únicamente queda encogerse de hombros.

Ello justificaría, en plenitud, la instauración del devenir puramente biográfico de nuestra intimidad, en antípoda a la gesta del Estadopartido en su conquista monumental del tiempo irreversible. Precisamente, el paisaje doméstico que la instalación manifiesta, no es sino la sedimentación del tiempo privatizado de la épica familiar chilena que, de alguna manera, pone en evidencia el triunfo del tiempo cíclico de lo económica, subyace el devenir naturalizado del

[3] El estado normal del capitalismo es la revolución permanente de sus propias condiciones de existencia: desde el principio el capitalismo "se pudre", está marcado por una contradicción mutiladora, por la discordia, por una necesidad inmanente de equilibrio: esta es exactamente la razón de que cambie y se desarrolle incesantemente -el desarrollo incesante es el único modo que tiene para resolver una y otra vez, llegar a un acuerdo con su propio y fundamental desequilibrio constitutivo, la "contradicción"-. Lejos de ser constrictivo, su límite es, así pues, el ímpetu mismo de su desarrollo (Žižek, 2003, p. 84). 
cotidiano que ahora ocupa el lugar vacante de la Historia.

Es este virtual fracaso de la historicidad el que faculta que ambas revoluciones, la cultural China y la neoliberal chilena, ahora se abracen en el "mismo día" del capitalismo mundial. La metáfora espacial de la antípoda, es justamente la que convierte al tiempo privado de lo doméstico en el espejo que intercede en dicho encuentro.

En la exposición, la progresiva destitución de lo público por hiperinflación de lo privado se pone de manifiesto únicamente respecto del espacio: de allí el imperativo de que la ciudad actual cambie sus paradigmas para adaptarse al nuevo estado de desarrollo humano. Sin embargo, en relación a la querella del tiempo, ninguna mención se desliza, al menos, en la declaración oficial de la muestra. Pareciera como si la descripción a posteriori de toda verdadera catástrofe estuviese siempre inevitablemente determinada por los propios efectos del desastre que se intenta describir.

De la misma manera, si el tenor general de la crítica de la exposición gira en torno a la tensión entre lo público y lo privado -entre Estado y mercado- de la cual principalmente el espacio se ofrece como protagonista, la crisis de la historicidad queda sepultada bajo la fantasía triunfante del cotidiano "mismo día" de la economía global que ese espacio promociona. Él encarna en la intimidad de sus enseres y su decorado, la lapidaria declaración que la utopía liberal hace del presente como "fin de la historia".

\section{LA COTIDIANIDAD COMO SÍNTOMA: SEÑALES DE VIDA}

Si la historia y su colapso han quedado de esta forma al descubierto, es debido a lo que la ficción del interior doméstico fue capaz de proporcionarnos. Es en la puesta en obra donde la decoración interior en cuanto fenómeno, muestra su cifra más profunda y que tiene que ver, por lo visto, con la crisis de la temporalidad contemporánea. Pero ha sido en el trabajo del arte y no ciertamente en el del diseño en donde tal condición se posibilita. Mientras que en el ámbito profesional de este último la decoración interior aún está atrapada en los lindes de la cotidianidad y, por tanto, sigue en deuda con la pesada naturalización que esta involucra, en el arte, en cambio, se hace visible el carácter eminentemente ficcional que la atraviesa. Al parecer, solo a través de la obra de arte la decoración interior puede revelarse como la fantasía que recubre el desastre de la historicidad.

Según esta hipótesis, podríamos sostener que el modo en que la cotidianidad doméstica se despliega en la instalación que hemos analizado, permite considerar que el crecimiento exponencial del interés actual por la decoración interior, es un síntoma de la catástrofe contemporánea, tanto del espacio (públicometropolitano) como del tiempo (histórico). Justamente, el síntoma se define como aquel elemento particular que viene a subvertir su propio fundamento universal, o en otras palabras, una especie que trastorna al mismo género al cual pertenece (Žižek, 2003).

Pues bien, si para el urbanismo moderno el domicilio se concebía como pieza integral de la ciudad, para las lógicas urbanas neoliberales la privatización del habitar se caracteriza por un progresivo desmarque de lo residencial respecto de la tradicional espacialidad pública ${ }^{[4]}$. La creciente preocupación de las últimas décadas por el agenciamiento estético de los espacios domiciliarios por parte de los sectores medios, es parte de las estrategias de re-enclasamiento que realizan tras la pérdida de su identificación con el sector público. Tras dicha demanda, el espacio domiciliario se constituye en el elemento particular que, separado de la universalidad metropolitana, ahora intenta subvertirla a través del consumo simultáneamente identificador y diferenciador de los "estilos de vida". De este modo, las comunidades plurales del gusto parecen presionar por el reemplazo definitivo de la comunidad de los derechos políticos.

Por otro lado, la particularidad cíclica del tiempo cotidiano ahora emerge como la universalidad del ritmo circular del mercado: el interior doméstico no solo se vuelve adicto a la innovación de manera análoga al frenesí del reemplazo de las mercancías, sino también melancólico, al momento en que ningún "estilo" del pasado tiene negada su ciudadanía en él. En buenas cuentas, todas las épocas pueden darse cita en la escena contemporánea del paisaje interior domiciliario, anulando la conciencia de lo absolutamente irreversible.

Es mediante esta doble subversión de lo particular respecto de lo universal, que la inflación posmoderna de lo decorativo se revela como síntoma de la catástrofe del tiempo y del espacio modernos. La plausibilidad de ello está a la mano. Recordemos que fue en la decoración donde se manifestó sintomáticamente la "falta de unidad de estilo" en los artefactos y utensilios de la Gran Exposición Universal de 1851. Es en honor a ese acontecimiento que reparamos el inevitable enganche entre la grandilocuencia histórica de las exposiciones universales y la particularidad microscópica de las formas

[4] Este es el fenómeno que Edward Soja denomina exópolis, entendido como un proceso de fractura de la totalidad metropolitana tras la separación tanto funcional como estética de los modos de vida periféricos, donde la ciudad frontera o Edge-city, se organiza de modo independiente de los grandes espacios públicos y equipamientos metropolitanos, optando por una vida altamente privatizada aunque, al mismo tiempo, urbanizada mediante la conexión de las zonas residenciales con autopistas y centros comerciales donde ya no es necesario "viajar" al centro de la ciudad para abastecerse o trabajar. Soja señala numerosas metáforas descriptivas del mismo fenómeno: "la metrópolis invertida", la "ciudad vuelta al revés", "urbanización periférica" y, en un sentido extenso, el término posmetrópolis (Soja, 2008, p. 340). Lo interesante, es que esta lógica de autonomización y de prescindencia de los equipamientos y espacio públicos, se empieza a reproducir ya no solo en la periferia, sino en el propio interior del tejido urbano tradicional. A este fenómeno pertenecen el creciente rol de "paracentros" que los grandes centros comerciales -o Shopping Mall- empiezan a ejercer como promotores de la "condominización" residencial, típicamente periférica. 


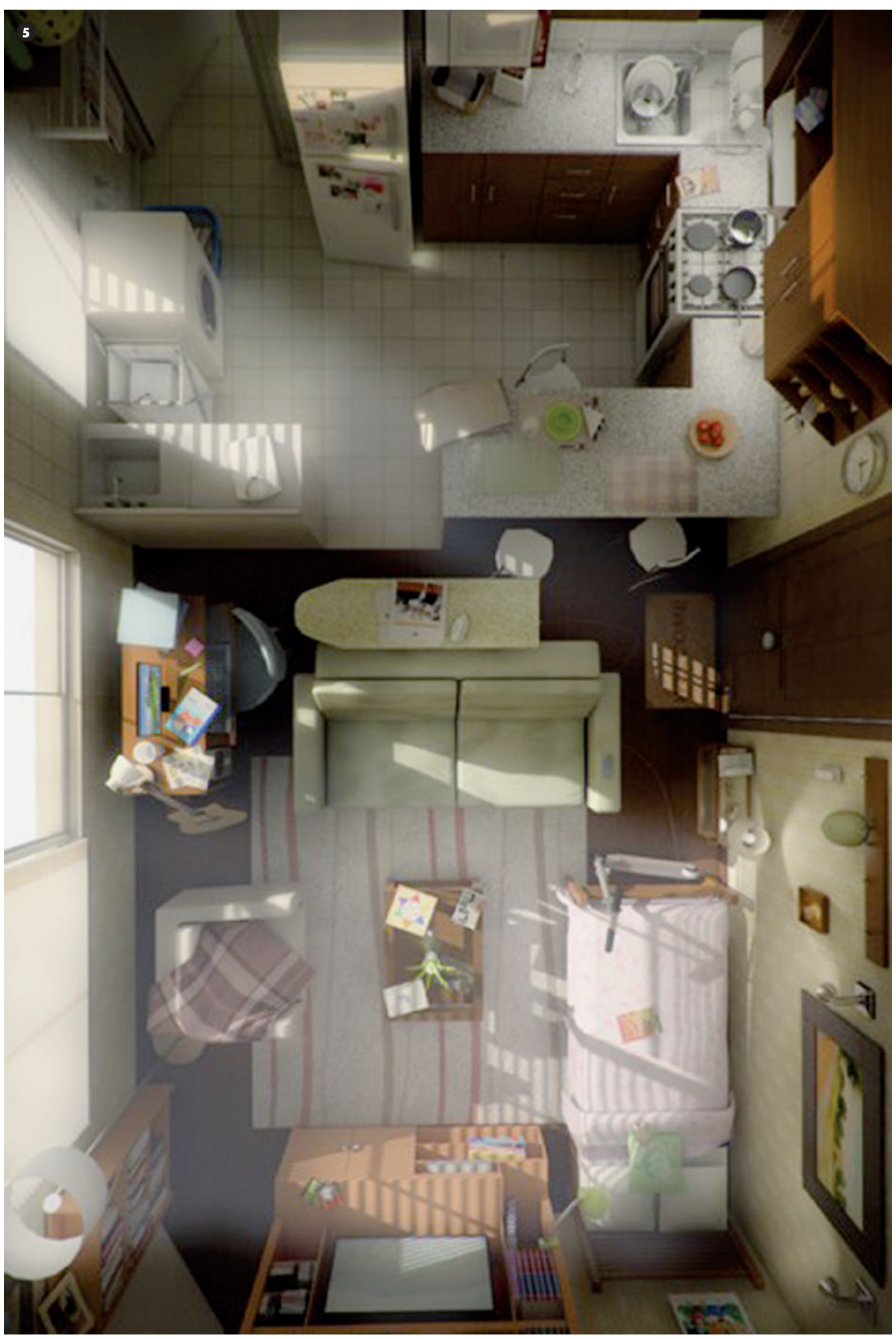

que habitan la especialidad privada y su comprimida temporalidad doméstica. Más aún, fue precisamente el ornamento el que fue considerado "delito" por parte de la modernidad arquitectónica, al incriminarlo como causa principal de aquella falta de unidad (Loos, 1972). Por último, no podemos olvidar que el propio posmodernismo interpretó el formalismo decorativo como signo de recuperación de la dimensión simbólica reprimida por el diseño de vanguardia, en donde la forma ahora comparece emancipada de su estricto apego a la univalencia de la función (Venturi, 2011).

Si en todos estos casos la decoración se ha comportado como síntoma, entonces debemos indagar el modo en que ella nos remite a la herida de la cual es actualmente su manifestación.

Benjamin nos dice que no hay documento de la cultura que no sea, al mismo tiempo, expresión de la barbarie (Benjamin, 2002). Las formas más excelsas y exquisitas de una civilización triunfante, siempre se sostienen sobre la violencia que antaño las hizo posible. Por lo mismo, después de todo evento traumático, sea este una catástrofe o un accidente, quienes pretenden ir al rescate deben tomar, como primera medida, la búsqueda de señales de vida.

En medio de un territorio arrasado por la tragedia, la tarea consiste en leer los signos, en husmear las huellas de lo que pueda haber sobrevivido. Esa es, en efecto, la labor de la historiografía. Sin embargo, el asunto se vuelve particularmente más complejo, si lo que se encuentra arrasado es el tiempo mismo. Es allí donde la propia posibilidad del trabajo histórico se vuelve complejo.

Por cierto, una de esas "señales de vida" consiste en el singular modo en que la decoración interior y la placidez cotidiana se convierten en la "unidad de estilo" de nuestros tiempos de mercado. En tanto síntomas de la catástrofe de la historia, esas señales manifiestan la naturaleza problemática del encuentro entre decoración 
e historiografía, ya que, más allá de la simple aplicación de una metodología de investigación a uno de los tantos objetos posibles de indagación histórica, por lo visto, la decoración parece ser su grado cero.

En esta inédita circunstancia, la búsqueda de señales de vida requiere de una operación reflexiva sobre los mismos recursos que la historiografía moviliza a la hora de intentar narrar lo ocurrido, antes de comenzar cualquier cuenta del devenir de lo decorativo. La reflexión, entendida como el modo en que el sujeto se vuelve consciente de sus operaciones cognitivas, aquí indica la manera en que la historia del diseño indaga sus propios recursos de representación, para efectos de atravesar la fantasía que aquellas señales construyen a la hora de intentar cubrir la catástrofe de la que son, precisamente, sus síntomas. Por lo pronto, ello nos obliga a rastrearlas en el lugar donde la fantasía se anuncie como tal. Ese lugar es el arte, ya que en el campo del diseño, como veremos, lo imaginario se recubre siempre con la pretensión de realidad.

Parte de esas señales de vida son las que hemos intentado vislumbrar en la muestra de Shanghai 2010, particularmente en el modo en que la identidad nacional del Chile neoliberal es ficcionada a través del "típico" interior doméstico de la nueva clase media aspiracional. Sin duda la privatización urbana y la reducción de la historia a lo cotidiano que aquel revela, son muestras de la catástrofe espacio-temporal del habitar de la posdictadura. Pero ha sido en la antípoda a ese gran "Otro" y su "retorno al remitente" donde ella se ha hecho visible, al momento de querer dar cuerpo a la gran ilusión nacional del "nosotros". No es casual que con la misma rapidez con que un pabellón de exposición es desmantelado tras cumplir su cometido, el bicentenario haya pasado tan rápidamente al olvido, tanto en la escena política como en la mediática, ciertamente aquellos ámbitos que solemos identificar como "espacios públicos" por excelencia. Ello es la mejor muestra de que, después de la fiebre conmemorativa, todo haya vuelto a la intimidad de nuestros asuntos y su gris cotidianidad -si es que alguna vez salimos de ella-y, por cierto, a la mera administración tecnocrática de un Estado con cada vez menos densidad y vocación histórica.

\section{BIBLIOGRAFÍA}

Aristía, T. (2009). "Arreglando la casa propia" en Manuel Tironi, Fernando Pérez Oyarzún, SCL: Espacio, prácticas y cultura urbana. Santiago: Pontificia Universidad Católica de Chile.

Benjamin, W. (2002). La dialéctica en suspenso. Fragmentos sobre la Historia. Traducción de Pablo Oyarzún. Santiago: ARCIS-LOM ediciones.

Candina, A. (2009). Por una vida digna y decorosa. Clase media y empleados públicos en el siglo XX chileno. Santiago: Universidad de Chile.
Debord, G. (1995). La sociedad del espectáculo. Santiago: Ediciones Naufragio.

Gaete, M. (2010); El pabellón de Chile en la Expo Shanghai 2010: una mirada desde el interior en www. plataformaarquitectónica.cl. Consultada en julio de 2011.

Lacan, J. (2008).; Escritos (2 volúmenes). Buenos Aires: Editorial Siglo XXI.

Maderuelo, J. (2006). El paisaje. Génesis de un concepto. Madrid: Abada editores.

Nietzsche F. (2000). De la utilidad y de los inconvenientes de los estudios históricos para la vida. Madrid: Edaf.

Somerville, H. (2010). Presentación Expo Shanghai 2010 en www.expo2010.cl.

Venturi, R.; Izenour, S.; Scott Brown, D. (2011). Aprendiendo de las Vegas. El Simbolismo olvidado de la forma arquitectónica. Barcelona: Gustavo Gili.

Yáñez, G.; Orellana, A.; Figueroa, O.; Arenas, F. (2008). Ciudad, Poder, Gobernanza. Santiago: Eure Libros Pontificia Universidad Católica de Chile.

Žižek, S. (2003). El sublime objeto de la ideología. Buenos Aires: Editorial Siglo XXI

Žižek, S. (2011). En defensa de causas perdidas. Madrid: Akal.

Soja, E. (2008). Postmetrópolis. Estudos críticos sobre las ciudades y las regiones. Madrid: Traficantes de sueños.

Sitios web www.expo2010.cl consultada en julio de 2011 . www. plataformaarquitectura.cl 